\title{
ASYMMETRIC EXPECTATION EFFECTS OF REGIME SHIFTS IN MONETARY POLICY
}

\author{
Zheng Liu \\ Federal Reserve Bank of San Francisco \\ and Emory University \\ Daniel F. Waggoner \\ Federal Reserve Bank of Atlanta \\ Tao Zha \\ Federal Reserve Bank of Atlanta \\ and Emory University
}

September 2008

Working Paper 2008-22

http://www.frbsf.org/publications/economics/papers/2008/wp08-22bk.pdf

The views in this paper are solely the responsibility of the authors and should not be interpreted as reflecting the views of the Federal Reserve Bank of San Francisco or the Board of Governors of the Federal Reserve System. 


\title{
ASYMMETRIC EXPECTATION EFFECTS OF REGIME SHIFTS IN MONETARY POLICY
}

\author{
ZHENG LIU, DANIEL F. WAGGONER, AND TAO ZHA
}

\begin{abstract}
This paper addresses two substantive issues: (1) Does the magnitude of the expectation effect of regime switching in monetary policy depend on a particular policy regime? (2) Under which regime is the expectation effect quantitatively important? Using two canonical DSGE models, we show that there exists asymmetry in the expectation effect across regimes. The expectation effect under the dovish policy regime is quantitatively more important than that under the hawkish regime. These results suggest that the possibility of regime shifts in monetary policy can have important effects on rational agents' expectation formation and on equilibrium dynamics. They offer a theoretical explanation for the empirical possibility that a policy shift from the dovish regime to the hawkish regime may not be the main source of substantial reductions in the volatilities of inflation and output.
\end{abstract}

Date: September 26, 2008.

Key words and phrases. Rational expectation; Imperfect credibility; Inflation; Monetary policy; Macroeconomic volatility; Lucas critique.

JEL classification: E32, E42, E52.

We are grateful to David Backus, Jean Boivin, Jeff Campbell, V. V. Chari, Roger Farmer, Marc Giannoni, Marvin Goodfriend, Alejandro Justiniano, Nobu Kiyotaki, Eric Swanson, John Williams, an anonymous referee, and especially Michael Golosov and Richard Rogerson for helpful suggestions and discussions. Jean Boivin and Marc Giannoni kindly provided us with their Matlab code for computing MSV solutions. We are grateful to Joan Gieseke for editorial assistance. Liu wishes to thank the Federal Reserve Banks of Atlanta and Minneapolis for their hospitality. The views expressed herein are those of the authors and do not necessarily reflect the views of the Federal Reserve Banks of Atlanta and San Francisco or the Federal Reserve System. 
[Lucas (1976)] has expressed the view that it makes no sense to think of the government as conducting one of several possible policies while at the same time assuming that agents remain certain about the policy rule in effect.

Cooley, LeRoy, and Raymon (1984, p. 468)

Explicit modelling of the connection of expectation-formation mechanisms to policy [regime] in an accurately identified model would allow better use of the data.

Sims (1982, p. 120)

\section{INTRODUCTION}

Consider monetary policy that follows a Taylor rule, in which the nominal interest rate is adjusted to respond to its own lag and deviations of inflation from its target value and of output from its trend. Suppose there are two monetary policy regimes, where the interest rate responds to inflation more strongly in the second regime (a hawkish regime) than it does in the first regime (a less hawkish or dovish regime). In this policy environment, it is often assumed that when monetary policy enters a particular regime, rational agents naively believe that the regime will prevail indefinitely (see, for example, Clarida, Galí, and Gertler (2000), Lubik and Schorfheide (2004), Boivin and Giannoni (2006)). This assumption, however, does not square well with the rational expectations view in that agents form expectations based on all available information, including possible changes in future policy. This point has been elaborated by Sims (1982), Sargent (1984), Barro (1984), Cooley, LeRoy, and Raymon (1984), and Sims (1987), among others. These authors argue that in an economy where past changes in monetary policy rules are observable and future changes are likely, rational agents' information set should include a probability distribution over possible policy shifts in the future. The difference between equilibrium outcome from a model that ignores probabilistic shifts in future policy regime and that from a model that takes into account such expected changes in regime reflects the key expectation-formation aspect of the Lucas critique, as implied by the antecedent two epigraphs. We call this difference the "expectation effect of regime shifts" in monetary policy.

This paper answers two theoretical questions that are of substantive importance. Is the magnitude of the expectation effect of regime switching the same across policy regimes? If not, under which regime the expectation effect is quantitatively important or unimportant? To answer the first question, we obtain closed-form solutions for two 
dynamic stochastic general equilibrium (DSGE) models, one is a stylized flexible-price model and the other is a canonical sticky-price model. Our main finding is that the importance of the expectation effect depends on monetary policy regime. In particular, we show that no matter whether the price is sticky or not, the expectation effect of regime switching under the hawkish policy regime is smaller than that under the dovish regime. The farther apart the two policy regimes, the larger the difference between the expectation effects under the two regimes.

To quantify the importance of the expectation effect on dynamics of inflation and output, we simulate the sticky-price model with several sources of plausible frictions. Our simulated results show that the magnitude of the expectation effect depends more on how strong propagation mechanisms are and less on how persistent the prevailing regime is. The stronger the propagation mechanism is, the more impact on inflation and output the expectation of future regime change has. While in theory the expectation effect disappears if the prevailing regime lasts indefinitely, we find that in practice the expectation effect under the dovish policy regime is quantitatively important even if the regime is very persistent. This conclusion holds for different models and under different scenarios, as shown in Section IV.

The asymmetry in the expectation effect of regime switches in monetary policy provides a theoretical insight into the empirical difficulty of finding changes in monetary policy as a main source of substantial reductions in macroeconomic volatility (Stock and Watson, 2003; Sims and Zha, 2006; Cecchetti, Hooper, Kasman, Schoenholtz, and Watson, 2007). This expectational asymmetry arises because either the hawkish stance of monetary policy in place or the expectation of switching to hawkish policy in the future influences agents' inflation expectations in a nonlinear way. As the expectation effect under the dovish regime can considerably alter the dynamics of key macroeconomic variables, caution needs to be taken in interpreting empirical models that are used to fit a subsample that covers only the dovish regime. In the hawkish policy regime, on the other hand, the expectation effect is small even if agents expect that the regime will shift to the dovish regime with a non-trivial probability, as hawkish policy itself anchors inflation expectations. Thus, even if a newly instituted hawkish regime is not perfectly credible, such as the Volcker disinflation studied by Erceg and Levin (2003) and Goodfriend and King (2005), inflation fluctuations can still be effectively stabilized. 


\section{Relation to the Literature}

There has been a growing strand of literature on Markov-switching rational expectations models. Examples include Andolfatto and Gomme (2003), Leeper and Zha (2003), Schorfheide (2005), Svensson and Williams (2005), Farmer, Waggoner, and Zha (2006), and Davig and Leeper (2007). Following that strand of literature, we generalize the standard DSGE model by allowing the possibility of changes in policy regime to be part of the economic information set. ${ }^{1}$ Those earlier papers, however, did not study the asymmetric aspect of expectation effects of regime switching and how important quantitatively such an asymmetry is in explaining some empirical findings on the effects of monetary policy changes. Nor did those papers study different implications of the expectation effect under different regimes and the role of different propagation mechanisms in the asymmetry of expectation effects.

Our paper is related to but different from the issues of indeterminacy (determinacy) of the equilibrium, which are the focus of the earlier work by Davig and Leeper (2007) and Farmer, Waggoner, and Zha (2008). First, there exists no theoretical result in the literature regarding determinacy vs. indeterminacy for Markov-switching DSGE models, like ours in this paper, that involve lagged endogenous variables such as consumption and inflation. ${ }^{2}$ Second, the asymmetry of expectation effects exists no matter whether the equilibrium is unique or not. The dovish regime in our paper does not necessarily correspond to an indeterminate regime; it simply represents a less hawkish regime. Even if monetary policy in both regimes raises the interest-rate instrument more than one for one in response to inflation, there exists the asymmetry of expectation effects across regimes as shown in Section IV.4.

The equilibrium in our regime-switching model is not always determinate and in the case of indeterminacy one needs to select an equilibrium. The particular equilibrium selection device we focus on in this paper is the minimum-state-variable (MSV) solution used, for example, by McCallum (1983), Svensson and Williams (2005), Farmer,

\footnotetext{
${ }^{1}$ We view this kind of regime-switching structural model as a starting point to study the quantitative importance of expectation effects of regime switching in monetary policy, as emphasized by Sims and Zha (2006) and Cecchetti, et al. (2007). An interesting issue that remains to be addressed is to what extent the probability of a regime shift is affected by the state of the economy or by the factors other than economic ones. This issue, deserving a separate investigation, is beyond the scope of this paper.

${ }^{2}$ In the context of a simple Markov-switching new-Keynesian model that does not involve any lagged endogenous variables, the debate on whether or not there is determinacy of the equilibrium and on how one should restrict one's attention to a subset of equilibria can be found in Davig and Leeper (2007) and Farmer, Waggoner, and Zha (2008).
} 
Waggoner, and Zha (2006), and Boivin and Giannoni (2006). It is important, however, to understand other solutions (i.e., sunspot solutions) and their impact on equilibrium dynamics. As shown in Farmer, Waggoner, and Zha (2007), there always exists a scale parameter in sunspot solutions that can arbitrarily affect the magnitude of the impact of a sunspot shock on inflation and output. Consequently, the expectation effect of a regime shift can be arbitrarily large or arbitrarily small, depending on the arbitrary value of this scale parameter. For this economic reason, we restrict the expectation effects to the MSV solution that concerns fundamental shocks only.

Our paper contributes to the literature by examining the theoretical properties and quantitative importance of the expectation effect of regime shifts in monetary policy. If the expectation effect turns out to be quantitatively unimportant, as in our hawkish regime, the equilibrium outcome in a model that ignores changes in future policy regime can be nevertheless a good approximation to the rational expectations equilibrium. If the expectation effect is quantitatively large, however, it is crucial to assess the impacts of the possibility of regime shifts on the equilibrium dynamics of inflation and output, as in our dovish regime. Our finding that the quantitative importance of the expectation effect depends on policy regime provides theoretical insights that help interpret the effects of monetary policy across different regimes.

\section{Theoretical Results}

To obtain closed-form analytical results of key properties of the expectation effect, we study two canonical DSGE models, one with flexible prices and one with sticky prices. Using the closed-form results, we show that our theoretical conclusions hold for both types of models.

III.1. The flexible-price model. Consider an endowment economy in which a oneperiod risk-free nominal bond is traded. The representative agent maximizes the utility

$$
\mathrm{E} \sum_{t=0}^{\infty} \beta^{t} A_{t} \frac{C_{t}^{1-\gamma}}{1-\gamma}
$$

subject to the budget constraint

$$
P_{t} C_{t}+B_{t}=P_{t} Y_{t}+R_{t-1} B_{t-1}
$$

where $C_{t}$ denotes consumption, $Y_{t}$ denotes the endowment, $P_{t}$ denotes the price level, $B_{t}$ denotes the agent's holdings of the bond, and $R_{t-1}$ denotes the nominal interest rate between period $t-1$ and $t$. The parameter $\beta \in(0,1)$ is a subjective discount factor and the parameter $\gamma>0$ measures the relative risk aversion. The endowment 
grows at a constant rate: $Y_{t+1} / Y_{t}=\lambda$. The preference shock $A_{t}$ follows the stationary stochastic process

$$
\ln A_{t}=\rho_{a} \ln A_{t-1}+\varepsilon_{a t},
$$

where $\rho_{a} \in(-1,1)$ and $\varepsilon_{a t}$ is an i.i.d. normal process with mean zero and variance $\sigma_{a}^{2}$.

The first order condition with respect to the bond holdings is given by

$$
\frac{A_{t} C_{t}^{-\gamma}}{P_{t}}=\beta \mathrm{E}_{t} \frac{A_{t+1} C_{t+1}^{-\gamma}}{P_{t+1}} R_{t}
$$

which describes the trade-off between spending a dollar today for current consumption and saving a dollar for future consumption.

Monetary policy follows the interest rate rule

$$
R_{t}=\kappa\left(\frac{\pi_{t}}{\pi^{*}}\right)^{\phi_{s_{t}}}
$$

where $\pi_{t}=P_{t} / P_{t-1}$ is the inflation rate, $\pi^{*}$ denotes the inflation target, $s_{t}$ denotes the realization of monetary policy regime in period $t, \phi_{s_{t}}$ is a regime-dependent parameter that measures the aggressiveness of monetary policy against deviations of inflation from its target, and $\kappa$ is a constant. Monetary policy regime follows a Markov-switching process between two states: a dovish regime characterized by $s_{t}=1$ and $0 \leq \phi_{1}<1$ and a hawkish regime by $s_{t}=2$ and $\phi_{2}>1$. The transition probabilities for the regime switching process are summarized in the $2 \times 2$ matrix

$$
Q=\left[\begin{array}{ll}
q_{11} & q_{12} \\
q_{21} & q_{22}
\end{array}\right],
$$

where $q_{i j}=\operatorname{Prob}\left(s_{t+1}=i \mid s_{t}=j\right)$. Each column of $Q$ sums up to 1 so that $q_{21}=1-q_{11}$ and $q_{12}=1-q_{22}$.

Market clearing implies that $C_{t}=Y_{t}$ and $B_{t}=0$ for all $t$. Using the goods market clearing condition, we can rewrite the intertemporal Euler equation as

$$
\beta \mathrm{E}_{t} \frac{A_{t+1}}{A_{t}}\left(\frac{Y_{t+1}}{Y_{t}}\right)^{-\gamma} \frac{R_{t}}{\pi_{t+1}}=1
$$

Thus, higher consumption (or income) growth requires a higher real interest rate.

III.1.1. Steady state and equilibrium dynamics. An equilibrium in this economy is summarized by the Euler equation (5) and the monetary policy rule (3). Since the endowment is exogenous, the variables of interest include the inflation rate $\pi_{t}$ and the nominal interest rate $R_{t}$.

In the steady-state equilibrium with $\varepsilon_{a t}=0$ for all $t$, we have

$$
\frac{R}{\pi}=\frac{\lambda^{\gamma}}{\beta} .
$$


We focus on the steady state in which the actual inflation equals the inflation target (i.e., $\pi=\pi^{*}$ ). It follows from the Euler equation that the steady-state nominal interest rate is given by $R=\frac{\lambda^{\gamma}}{\beta} \pi^{*}$. As is evident from the interest rate rule (3), the monetary authority is able to achieve the inflation target in the steady state if it sets $\kappa=\frac{\lambda^{\gamma}}{\beta} \pi^{*}$. Thus, although monetary policy switches between the two regimes, the steady-state solution does not depend on policy regime and thus allows us to log-linearize the equilibrium conditions around the constant steady state.

Log-linearizing the Euler equation (5) around the steady state results in

$$
\hat{R}_{t}=\mathrm{E}_{t} \hat{\pi}_{t+1}+\gamma\left(1-\rho_{a}\right) \hat{a}_{t}
$$

where $\hat{R}_{t}$ and $\hat{\pi}_{t}$ denote the log-deviations of the nominal interest rate and the inflation rate from steady state and $\hat{a}_{t}=\ln A_{t}$. A positive preference shock raises the real interest rate since a rise in $\hat{a}_{t}$ implies a stronger desire for consumption relative to saving and thus interest rate rises. Log-linearizing the interest rate rule (3) around the deterministic steady state leads to

$$
\hat{R}_{t}=\phi_{s t} \hat{\pi}_{t}
$$

Combining (6) and (7), we obtain the single equation that describes inflation dynamics:

$$
\phi_{s_{t}} \hat{\pi}_{t}=\mathrm{E}_{t} \hat{\pi}_{t+1}+\gamma\left(1-\rho_{a}\right) \hat{a}_{t}, \quad s_{t} \in\{1,2\} .
$$

III.1.2. The equilibrium solution. The state variable in the simple model (8) is the preference shock $\hat{a}_{t}$. Thus the solution takes the form $\pi_{t}=\alpha_{s_{t}} \hat{a}_{t}$, where $\alpha_{s t}$ is to be solved for $s_{t} \in\{1,2\}$. Denote

$$
A=\left[\begin{array}{cc}
\phi_{1}-\rho_{a} q_{11} & -\rho_{a} q_{21} \\
-\rho_{a} q_{12} & \phi_{2}-\rho_{a} q_{22}
\end{array}\right] .
$$

The following proposition gives the closed-form solution.

Proposition 1. The MSV solution to the regime-switching model (8) is given by

$$
\hat{\pi}_{t}=\alpha_{s_{t}} \hat{a}_{t}, \quad s_{t} \in\{1,2\}
$$

where

$$
\left[\begin{array}{l}
\alpha_{1} \\
\alpha_{2}
\end{array}\right]=A^{-1}\left[\begin{array}{l}
\gamma\left(1-\rho_{a}\right) \\
\gamma\left(1-\rho_{a}\right)
\end{array}\right],
$$

with the implicit assumption that the matrix $A$ is invertible.

Proof. See Appendix B.1. 
The solution represented by (9) implies that the volatility, measured by the standard deviation of inflation, is given by

$$
v_{\pi, 1}=\frac{\left|\alpha_{1}\right|}{\sqrt{1-\rho_{a}^{2}}} \sigma_{a}, \quad v_{\pi, 2}=\frac{\left|\alpha_{2}\right|}{\sqrt{1-\rho_{a}^{2}}} \sigma_{a} .
$$

III.1.3. Expectation effects. The solution (9) takes into account possible switches of future policy regime. This solution in general differs from that obtained under the simplifying assumption that agents believe that the current regime will continue permanently. The difference between these two solutions is what we call the expectation effect of regime switching.

To examine the underlying forces that drive the expectation effect, we consider the solution that rules out regime shifts in future policy, which is equivalent to solving the following model

$$
\phi_{j} \hat{\pi}_{t}=\mathrm{E}_{t} \hat{\pi}_{t+1}+\gamma\left(1-\rho_{a}\right) \hat{a}_{t}
$$

where $\phi_{j}(j=1,2)$ does not depend on time. Equilibrium condition (10) is a special case of condition (8) with $q_{j j}=1$ for $j \in\{1,2\}$. The solution to (10) is given by the following proposition.

Proposition 2. The MSV solution to the model described in (10) is

$$
\hat{\pi}_{t}=\bar{\alpha}_{j} \hat{a}_{t}, \quad \bar{\alpha}_{j}=\frac{\gamma\left(1-\rho_{a}\right)}{\phi_{j}-\rho_{a}}, \quad j \in\{1,2\},
$$

where it is assumed that $\phi_{j} \neq \rho_{a}$.

Proof. See Appendix B.2.

The solution represented by (11) implies that the volatility of inflation under the assumption that rules out changes in future policy regime is given by

$$
\bar{v}_{\pi, 1}=\frac{\left|\bar{\alpha}_{1}\right|}{\sqrt{1-\rho_{a}^{2}}} \sigma_{a}, \quad \bar{v}_{\pi, 2}=\frac{\left|\bar{\alpha}_{2}\right|}{\sqrt{1-\rho_{a}^{2}}} \sigma_{a} .
$$

The following proposition establishes the existence and the properties of the expectation effects of regime shifts in monetary policy. Specifically, we show that the volatility of inflation in the dovish regime decreases with the probability of switching to the hawkish regime and that the volatility of inflation in the hawkish regime increases with the probability of switching to the dovish regime. Thus, the expectation of regime switch affects inflation dynamics. 
Proposition 3. The MSV solution given by (9) has the property that $\alpha_{j}>0$ for $j \in$ $\{1,2\}$ and that

$$
\frac{\partial v_{\pi, 1}}{\partial q_{21}}<0, \quad \frac{\partial v_{\pi, 2}}{\partial q_{12}}>0,
$$

where we assume that $\phi_{1}>\rho_{a}$ so that $\bar{\alpha}_{j}>0$ for $j \in\{1,2\}$.

Proof. See Appendix B.3.

The expectation effect of regime switches can be measured by the magnitude $\left|\alpha_{j}-\bar{\alpha}_{j}\right|$ for $j=1,2$. Because $\bar{\alpha}_{j}$ does not depend on transition probabilities, Proposition 3 implies that the less persistent the regime $j$ is, the more significant the expectation effect $\left|\alpha_{j}-\bar{\alpha}_{j}\right|$ becomes.

III.1.4. Asymmetry. As one can see from (9), $\alpha_{j}$ is nonlinear in the model parameters. This nonlinearity implies that when the probabilities of switching are the same for both regimes (i.e., when $q_{11}=q_{22}$ ), the expectation effect may not be symmetric across the two regimes. This result is formally stated in the following proposition.

Proposition 4. Assume that $q_{11}=q_{22}$. If $\phi_{1}>\rho_{a}$ and $\alpha_{1}, \alpha_{2}>0$, then

$$
\frac{\bar{v}_{\pi, 1}-v_{\pi, 1}}{v_{\pi, 2}-\bar{v}_{\pi, 2}}=\frac{\phi_{2}-\rho_{a}}{\phi_{1}-\rho_{a}}>1
$$

Proof. See Appendix B.4.

In the dovish regime, as we show in Proposition 3, the expectation of switching to the hawkish regime stabilizes inflation fluctuations; in the hawkish regime, the expectation of switching to the dovish regime destabilizes inflation. Proposition 4 establishes that the stabilizing effect in the dovish regime exceeds the destabilizing effect in the hawkish regime. Moreover, the expectation effect becomes more asymmetric if the shock is more persistent, if monetary policy takes a stronger hawkish stance against inflation in the hawkish regime, or if policy is less responsive to inflation in the dovish regime. Since these results are derived from a simple model with flexible prices, we examine below whether or not these results survive in models with nominal and real rigidities.

III.2. The sticky-price model. We have shown that, in the flexible-price model, the possibility of regime-switching in monetary policy generates expectation effects that stabilize inflation in the dovish regime and destabilize it in the hawkish regime. Furthermore, the expectation effect can be asymmetric across regimes: the stabilizing effect of regime shifts tends to be larger in magnitude than the destabilizing effect. Do these results hold for economies with richer and more realistic equilibrium dynamics? To answer this question, we study a stylized sticky-price model. 
Our model structure is standard in the DSGE literature (Christiano, Eichenbaum, and Evans, 2005). The model features monopolistic competition in the intermediate goods market, where firms producing differentiated products set their prices in a staggered fashion (Calvo, 1983). Under the Calvo price contracts, a fraction of firms can reoptimize their pricing decisions in each period and the rest cannot. If a firm cannot reoptimize, it is allowed to index its price to the previous period inflation. The representative household consumes a final good, which is a Dixit-Stiglitz composite of differentiated intermediate goods. The household is endowed with a unit of time and supplies labor to intermediate goods producers in a competitive labor market. We follow the literature and allow for two sources of real rigidities in the forms of habit formation in consumption and firm-specific factors in production. We present the details of the model in Appendix A.

To study the implications of regime shifts in monetary policy, we generalize the standard DSGE model by allowing the coefficients in the Taylor rule to vary with policy regime. Specifically, the monetary authority follows the interest-rate rule

$$
R_{t}=R_{t-1}^{\rho_{r, s_{t}}}\left[\kappa_{s_{t}}\left(\frac{\pi_{t}}{\pi^{*}}\right)^{\phi_{\pi, s_{t}}} \tilde{Y}_{t}^{\phi_{y, s_{t}}}\right]^{1-\rho_{r, s_{t}}} e^{\varepsilon_{r t}},
$$

where $R_{t}$ denotes the nominal interest rate, $\tilde{Y}_{t}$ denotes detrended aggregate output, $\pi_{t}$ denotes inflation, $\pi^{*}$ denotes the inflation target, and the policy parameters $\kappa_{s t}, \rho_{r, s_{t}}$, $\phi_{\pi, s_{t}}$, and $\phi_{y, s_{t}}$ depend on the regime $s_{t}$, which follows the same Markov transition process described in (4). The term $\varepsilon_{r t}$ is a shock to monetary policy and follows an i.i.d. normal process with mean zero and variance $\sigma_{r}^{2}$. In addition to the monetary policy shock, the economy is buffeted by three other shocks, a preference shock $A_{t}$ that follows the stochastic process as described in (1), a technology shock and a markup shock to be described below. The agents observe all shocks and monetary policy regime before making optimizing decisions.

Regime shifts in monetary policy can potentially complicate the computation of equilibrium dynamics as the steady-state equilibrium may vary with policy regime. We show that, with an appropriate choice of the scale parameter $\kappa_{s_{t}}$ in the interest rate rule, the monetary authority is able to achieve its inflation target in the steady state and the steady-state equilibrium is independent of policy regime. This result is summarized in the following proposition.

Proposition 5. In steady state equilibrium, real variables such as aggregate output, consumption, hours, and the real wage are independent of monetary policy and are thus invariant to regime shifts in policy. Further, if the scale parameter $\kappa_{s_{t}}$ in the 
interest rate rule satisfies

$$
\kappa_{s_{t}}=\frac{\lambda}{\beta} \pi^{*} \tilde{Y}^{-\phi_{y, s_{t}}},
$$

where $\lambda$ is the exogenous trend growth rate of productivity, $\beta$ is the subjective discount factor, and $\tilde{Y}$ is the steady-state detrended output that is independent of policy, then the steady-state nominal variables are given by $\pi=\pi^{*}$ and $R=\frac{\lambda}{\beta} \pi^{*}$, which are also invariant to regime shifts in policy.

Proof. See Appendix A.1.

In what follows, we present log-linearized equilibrium conditions around the deterministic steady state which, according to Proposition 5, is invariant to policy regime.

Log-linearizing the optimal pricing decision rule leads to the Phillips curve relation

$$
\begin{aligned}
& \hat{\pi}_{t}-\iota \hat{\pi}_{t-1}=\beta \mathrm{E}_{t}\left(\hat{\pi}_{t+1}-\iota \hat{\pi}_{t}\right) \\
& \quad+\psi\left[\frac{\xi+1}{\alpha} \hat{y}_{t}+\frac{b}{\lambda-b}\left(\hat{y}_{t}-\hat{y}_{t-1}+\hat{\nu}_{t}\right)\right]+\psi \hat{\mu}_{t},,
\end{aligned}
$$

where $\xi$ is the inverse Frisch elasticity of labor supply, $\iota$ is the inflation-indexation parameter, $b$ is the habit-formation parameter, and $\alpha$ is the elasticity of output with respect to the labor input. The parameter $\psi$ is a composite of other parameters given by

$$
\psi=\frac{(1-\beta \eta)(1-\eta)}{\eta} \frac{1}{1+\theta(1-\alpha) / \alpha},
$$

where $\theta$ is the elasticity of substitution between differentiated intermediate goods. The variable $\hat{\pi}_{t}$ denotes the inflation rate and the variable $\hat{y}_{t}$ denotes detrended output, both are deviations from the steady-state values. The term $\hat{\nu}_{t} \equiv \ln \nu_{t}$ is the technology shock, which follows the stationary stochastic process

$$
\ln \nu_{t}=\rho_{\nu} \ln \nu_{t-1}+\varepsilon_{\nu t},
$$

where $\rho_{\nu} \in[0,1)$ and $\varepsilon_{\nu t}$ is a white-noise process with mean zero and variance $\sigma_{\nu}^{2}$. The term $\hat{\mu}_{t} \equiv \ln \left(\mu_{t} / \mu\right)$ is the markup shock, which follows the stationary stochastic process

$$
\ln \mu_{t}=\left(1-\rho_{\mu}\right) \ln \mu+\rho_{\mu} \ln \mu_{t-1}+\varepsilon_{\mu t},
$$

where $\mu$ denotes the average markup, $\rho_{\mu} \in[0,1)$ measures the persistence of the markup shock, and $\varepsilon_{\mu t}$ follows an i.i.d. normal process with mean zero and variance $\sigma_{\mu}^{2}$.

Log-linearizing the intertemporal Euler equation leads to the IS-curve relation

$$
\begin{aligned}
& \mathrm{E}_{t} \hat{y}_{t+1}-\frac{\lambda+b}{\lambda} \hat{y}_{t}+\frac{b}{\lambda} \hat{y}_{t-1}= \\
& \quad\left(1-\frac{b}{\lambda}\right)\left(\hat{R}_{t}-\mathrm{E}_{t} \hat{\pi}_{t+1}\right)+\left(\frac{b}{\lambda}-\rho_{\nu}\right) \hat{\nu}_{t}-\frac{(\lambda-b)\left(1-\rho_{a}\right)}{\lambda} \hat{a}_{t},
\end{aligned}
$$


where $\hat{R}_{t}$ denotes the deviations of the nominal interest rate from steady state.

Finally, the first-order approximation to the interest rate rule (14) leads to

$$
\hat{R}_{t}=\rho_{r, s_{t}} \hat{R}_{t-1}+\left(1-\rho_{r, s_{t}}\right)\left[\phi_{\pi, s_{t}} \hat{\pi}_{t}+\phi_{y, s_{t}} \hat{y}_{t}\right]+\varepsilon_{r t} .
$$

To derive closed-form solutions and obtain analytical characterizations of the expectation effects of regime switching, we begin with a simplified version of the model with $b=\iota=0, \alpha=1, \rho_{r, s_{t}}=0$, and $\phi_{y, s_{t}}=0$ and we focus on dynamic responses of inflation to the preference shock. ${ }^{3}$ In Section IV we analyze the expectation effects in more general cases based on simulation results. With our simplifying assumptions about the parameters, our model reduces to the standard three-equation New Keynesian model:

$$
\begin{aligned}
\hat{\pi}_{t} & =\beta \mathrm{E}_{t} \hat{\pi}_{t+1}+\psi(1+\xi) \hat{y}_{t}, \\
\hat{y}_{t} & =\mathrm{E}_{t} \hat{y}_{t+1}-\left[\hat{R}_{t}-\mathrm{E}_{t} \hat{\pi}_{t+1}\right]+\left(1-\rho_{a}\right) \hat{a}_{t}, \\
\hat{R}_{t} & =\phi_{s_{t}} \hat{\pi}_{t} .
\end{aligned}
$$

Substituting out the variables $\hat{y}_{t}$ and $\hat{R}_{t}$ by using (21) and (23), we obtain the secondorder difference equation

$$
\beta \mathrm{E}_{t} \hat{\pi}_{t+2}-(1+\beta+\kappa) \mathrm{E}_{t} \hat{\pi}_{t+1}+\left(1+\kappa \phi_{s_{t}}\right) \hat{\pi}_{t}=\kappa\left(1-\rho_{a}\right) \hat{a}_{t},
$$

where the parameter $\kappa=\psi(1+\xi)$.

Since $\hat{a}_{t}$ is the only state variable, the MSV solution takes the form $\hat{\pi}_{t}=\gamma_{s_{t}} \hat{a}_{t}$, where $\gamma_{s_{t}}$ is to be solved for $s_{t} \in\{1,2\}$. The following proposition summarizes the MSV solution in the sticky-price model.

Proposition 6. The MSV solution to the regime-switching model (24) is given by

$$
\hat{\pi}_{t}=\gamma_{s_{t}} \hat{a}_{t}, \quad s_{t} \in\{1,2\}
$$

where

$$
\left[\begin{array}{l}
\gamma_{1} \\
\gamma_{2}
\end{array}\right]=A^{-1}\left[\begin{array}{l}
\kappa\left(1-\rho_{a}\right) \\
\kappa\left(1-\rho_{a}\right)
\end{array}\right],
$$

where the matrix $A$, defined below, is assumed to be invertible.

$A=\left[\begin{array}{cc}\kappa\left(\phi_{1}-\rho_{a} q_{11}\right)+\left(1-\rho_{a} q_{11}\right)\left(1-\beta \rho_{a} q_{11}\right)+\beta \rho_{a}^{2} q_{21} q_{12} & -\rho_{a} q_{21}\left[1-\beta \rho_{a} q_{22}+\beta\left(1-\rho_{a} q_{11}\right)+\kappa\right] \\ -\rho_{a} q_{12}\left[1-\beta \rho_{a} q_{11}+\beta\left(1-\rho_{a} q_{22}\right)+\kappa\right] & \kappa\left(\phi_{2}-\rho_{a} q_{22}\right)+\left(1-\rho_{a} q_{22}\right)\left(1-\beta \rho_{a} q_{22}\right)+\beta \rho_{a}^{2} q_{21} q_{12}\end{array}\right]$

Proof. See Appendix B.5.

To obtain the expectation effect of regime shifts, we compare the solution (25) with the constant-regime solution. The next proposition establishes the constant-regime solution.

\footnotetext{
${ }^{3}$ Our theoretical results hold for dynamic responses to other shocks.
} 
Proposition 7. The MSV solution to the model in which agents expect the particular regime $j$ to last forever is given by

$$
\hat{\pi}_{t}=\bar{\gamma}_{j} \hat{a}_{t}, \quad \bar{\gamma}_{j}=\frac{\kappa\left(1-\rho_{a}\right)}{\left(1-\rho_{a}\right)\left(1-\beta \rho_{a}\right)+\kappa\left(\phi_{j}-\rho_{a}\right)}, \quad j \in\{1,2\}
$$

where we assume that $\kappa\left(\phi_{1}-\rho_{a}\right)>-\left(1-\rho_{a}\right)\left(1-\beta \rho_{a}\right)$ so that $\bar{\gamma}_{j}>0$ for $j \in\{1,2\}$.

Proof. The constant-regime solution is a special case of the model (24) with $q_{i i}=1$ for $i \in\{1,2\}$.

The following two propositions establish the existence of the expectation effect. In particular, the volatility of inflation in the dovish regime decreases with the probability of switching to the hawkish regime, while the volatility in the hawkish regime increases with the probability of switching to the dovish regime. More formally, we define the volatilities of inflation under different scenarios as follows:

$$
\begin{array}{ll}
v_{\pi, 1}=\frac{\gamma_{1}}{\sqrt{1-\rho_{a}^{2}}} \sigma_{a}, & v_{\pi, 2}=\frac{\gamma_{2}}{\sqrt{1-\rho_{a}^{2}}} \sigma_{a}, \\
\bar{v}_{\pi, 1}=\frac{\bar{\gamma}_{1}}{\sqrt{1-\rho_{a}^{2}}} \sigma_{a}, & \bar{v}_{\pi, 2}=\frac{\bar{\gamma}_{2}}{\sqrt{1-\rho_{a}^{2}}} \sigma_{a} .
\end{array}
$$

Proposition 8. The MSV solution in (25) has the property that $\gamma_{j}>0$ for $j \in\{1,2\}$ and that

$$
\frac{\partial v_{\pi, 1}}{\partial q_{21}}<0, \quad \frac{\partial v_{\pi, 2}}{\partial q_{12}}>0
$$

Proof. See Appendix B.6.

Proposition 9. $\bar{v}_{\pi, 1}>v_{\pi, 1}$ and $\bar{v}_{\pi, 2}<v_{\pi, 2}$.

Proof. The proof follows directly from Appendix B.6.

We have established that the expectation effect can generate inflation dynamics different from those implied by the constant-parameter version of the model. We now show that the expectation effect is asymmetric even when the probability of switching is the same for both regimes (i.e., $q_{11}=q_{22}$ ). The result is summarized as follows.

Proposition 10. Assume that $q_{11}=q_{22}$. We have

$$
\frac{\bar{v}_{\pi, 1}-v_{\pi, 1}}{v_{\pi, 2}-\bar{v}_{\pi, 2}}=\frac{\left(1-\rho_{a}\right)\left(1-\beta \rho_{a}\right)+\kappa\left(\phi_{2}-\rho_{a}\right)}{\left(1-\rho_{a}\right)\left(1-\beta \rho_{a}\right)+\kappa\left(\phi_{1}-\rho_{a}\right)}>1 \text {. }
$$

Thus, as in the flexible-price model, the expectation effects in the sticky-price model here stabilize inflation fluctuations in the dovish regime and magnify inflation fluctuations in the hawkish regime. The stabilizing effect exceeds the magnifying effect. 


\section{Quantitative Importance of the Expectation Effect}

The theoretical results obtained in the previous sections provide key insight into why the expectation effect exists and how it can be asymmetric across regimes. But how important quantitatively is the expectation effect of regime shifts? How does the expectation effect affect equilibrium dynamics when monetary policy shifts from the dovish regime to the hawkish regime? We address these issues using the model presented in Section III.2. ${ }^{4}$ Specifically, we allow for several different sources of frictions and shocks. This generalization of the model makes it difficult to obtain closed-form solutions. We solve the model (16)-(20) numerically based on the parameter values described below. We study the expectation effects of regime shifts based on the simulated dynamics. With regime-dependent coefficients in the policy rule, the model is nonlinear and the solution method becomes nonstandard. We use the solution method developed by Farmer, Waggoner, and Zha (2006) to solve our Markov-switching rational expectations model. The specific steps that we take in solving the model are described in appendices of the earlier version of this paper (see Liu, Waggoner, and Zha (2007)).

To obtain numerical solutions to the model, we need to assign values to the parameters. In our regime-switching model, there are two sets of parameters. The first set of parameters is invariant to policy regime. This set includes $\beta$, the subjective discount factor; $b$, the habit parameter; $\xi$, the inverse Frisch elasticity of labor supply; $\alpha$, the elasticity of output with respect to labor; $\theta$, the elasticity of substitution between differentiated goods; $\lambda$, the trend growth rate of productivity; $\eta$, the Calvo probability that a firm cannot re-optimize its pricing decision; $\iota$, the degree of inflation indexation; and the parameters in the shock processes, such as $\mu, \rho_{\mu}$, and $\sigma_{\mu}$ for the markup shock, $\rho_{a}$ and $\sigma_{a}$ for the preference shock, $\rho_{\nu}$ and $\sigma_{\nu}$ for the technology shock, and $\sigma_{r}$ for the monetary policy shock. In addition, we need to assign values to the transition probabilities $q_{i j}$ for $i, j \in\{1,2\}$. The second set of parameters is regime-dependent. This set includes the policy parameters $\rho_{r, s_{t}}, \phi_{\pi, s_{t}}$, and $\phi_{y, s_{t}}$. Since some of the frictions in the model are not fully micro-founded, several parameters such as $\eta$ and $\iota$ are likely to vary with policy regime. In the baseline model, we treat these parameters as constant. In Section IV.6, we study a more general case when these parameters are allowed to depend on regime.

\footnotetext{
${ }^{4}$ This kind of model has been a workhorse for quantitative monetary analysis. See, for example, Galí and Gertler (1999), Chari, Kehoe, and McGrattan (2000), Ireland (2004), Lubik and Schorfheide (2004), CEE (2005), Boivin and Giannoni (2006), Del Negro, et al. (2007), and Smets and Wouters (2007).
} 
The baseline values of the parameters for our simulations are summarized in Table 1. These parameter values correspond to a quarterly model. We set $\lambda=1.005$ so that the average annual growth rate of per capital GDP is $2 \%$. We set $\beta=0.9952$ so that, given the value of $\lambda$, the average annual real interest rate (equal to $\lambda / \beta$ ) is $4 \%$. Following the literature, we set $b=0.75$, which is in the range considered by Boldrin, Christiano, and Fisher (2001). We set $\xi=2$, corresponding to a Frisch elasticity of 0.5 . We set $\alpha=0.7$, corresponding to a labor income share of $70 \%$. The substitution-elasticity parameter $\theta$ determines the steady-state markup and is set at 10, in line with the values used by Basu and Fernald (2002) and Rotemberg and Woodford (1997). We set $\eta=0.66$, so that the price contracts last for 3 quarters on average. Following Christiano, Eichenbaum, and Evans (2005), we set $\iota=1$ as the baseline value. For the parameters governing the shock processes, we set $\rho_{a}=\rho_{\mu}=0.9, \rho_{\nu}=0$ (implying a random walk technology shock process), and $\sigma_{a}=\sigma_{\mu}=\sigma_{\nu}=\sigma_{r}=0.1$. For the parameters in the transition matrix $Q$, we set $q_{11}=0.95$ and $q_{22}=0.95$ (and accordingly, $q_{21}=0.05$ and $q_{12}=0.05$ ). These parameter values imply that both regimes are highly persistent at quarterly frequency. While we report the results based on these parameter values, our conclusions about asymmetric expectation effects hold for a wide range of values of these parameters.

To focus on policy responses to inflation, we set $\rho_{r}=0.55$ and $\phi_{y}=0.5$ in both regimes and allow $\phi_{\pi}$ to vary across regimes. ${ }^{5}$ In our baseline simulation, we consider two considerably different policies represented by $\phi_{\pi, 1}=0.9$ for the dovish regime and $\phi_{\pi, 2}=2.5$ for the hawkish regime. These parameter values imply local equilibrium indeterminacy if the dovish regime is to stay indefinitely. In Section IV.4, we consider an alternative configuration of the policy parameters with $\phi_{\pi, 2}>\phi_{\pi, 1}>1$ to show the extent to which the quantitative importance of asymmetric expectation effects depends on equilibrium indeterminacy.

IV.1. Asymmetric expectation effects. To gauge the importance of the expectation effect when agents take into account possible switches in future policy regime, we compare the dynamic behavior of macroeconomic variables in our regime-switching model with that in the version of the model in which agents naively believe that the current regime would prevail indefinitely. We focus on the impulse responses of inflation and output. 6

\footnotetext{
${ }^{5}$ Note that our results hold even if $\rho_{r}$ is set to zero.

${ }^{6}$ For discussions about dynamic responses of other variables, see the working paper version Liu, Waggoner, and Zha (2007).
} 
Figures 1 and 2 display the impulse responses of inflation and output following each of the four shocks: the monetary policy shock ("MP"), the demand shock ("Demand"), the markup shock ("Markup"), and the technology shock ("Tech"). Within each subgraph, we plot two sets of impulse responses. One set corresponds to the version of the model where agents naively believe that the current regime will last indefinitely (the solid line), and the other set corresponds to the baseline model where agents take regime switching into account in forming their expectations (the dashed line). The difference between these two sets of impulse responses represents the expectation effect of regime switching in future policy. The left column of each figure displays impulse responses conditional on the dovish regime. The right column displays the responses conditional on the hawkish regime.

Figure 1 shows that, in the dovish regime (the left column), if agents take into account the effects of possible shifts in future regime, the responses of inflation to the demand shock and the markup shock are substantially dampened relative to those in the model in which agents naively believe that the dovish regime would last indefinitely. As one can see, even if the probability that policy switches to the hawkish regime is modest at 5\%, the expectation effect is quantitatively strong. If the dovish regime is less persistent so that it is more likely to switch to the hawkish regime, we find that the expectation effect is even stronger (nor reported here). Following the monetary policy shock and the technology shock, however, the expectation effects seem to be less pronounced. In the hawkish regime (the right column), when agents take into account the possibility of regime switching in the future, the responses of inflation are slightly amplified compared to those in the constant-regime model. The amplification effect in the hawkish regime is much weaker than the stabilizing effect in the dovish regime. This asymmetry of expectation effects arises because the existence of the hawkish regime and the possibility that policy may switch to that regime in the future help anchor agents' inflation expectations. This finding is consistent with the view that U.S. monetary policy since mid-1980s has been effective in stabilizing inflation despite the belief that this hawkish policy may not last forever (Bernanke and Mishkin, 1997; Mishkin, 2004; Goodfriend and King, 2005).

Figure 2 displays the impulse responses of output. As in the case with inflation, the expectation effect substantially dampens the responses of output in the dovish regime (in particular, following demand and markup shocks) and slightly amplifies output responses in the hawkish regime. Thus, the asymmetry of expectation effects holds for output as well, although to a lesser extent than it does for inflation. 
To gauge the quantitative importance of the expectation effect and the magnitude of its asymmetry across regimes, we compute the volatilities of inflation and output. The volatilities are derived from the solution to our structural model, which takes the following reduced form

$$
x_{t}=G_{1, s_{t}} x_{t-1}+G_{2, s_{t}} \epsilon_{t}
$$

where the matrices $G_{1, s_{t}}$ and $G_{2, s_{t}}$ are functions of the structural parameters. To derive the unconditional volatility of $x_{t}$ for regime $j(j=1,2)$, we fix $G_{1, s_{t}}=G_{1, j}$ and $G_{2, s_{t}}=G_{2, j}$ for all $t$ in $(29)$ and compute $\Omega_{j}^{\text {tot }}=E x_{t} x_{t}^{\prime}$ as

$$
\operatorname{vec}\left(\Omega_{j}^{\mathrm{tot}}\right)=\left(I-G_{1, j} \otimes G_{1, j}\right)^{-1} \operatorname{vec}\left(G_{2, j} G_{2, j}^{\prime}\right)
$$

The unconditional volatility of $x_{t}$ in regime $j$ is measured by the square root of the diagonal of $\Omega_{j}^{\text {tot }}$. The first two elements of $x_{t}$ are inflation and output; their volatilities are reported in Table 2.

A strong expectation effect in the dovish regime and the lack of it in the hawkish regime are evident by comparing the results across Panels $\mathrm{A}$ and $\mathrm{B}$ in Table 2 . In the dovish regime, the expectation of a shift to the hawkish regime lowers macroeconomic volatility, especially inflation volatility. The table shows that, when the expectation effect is taken into account, the unconditional volatility of inflation is lowered by about $60 \%$ (from 0.33 to 0.13 ). The output volatility is also reduced, although to a lesser extent (about a $24 \%$ reduction). In comparison, in the hawkish regime, the expectation of a shift to the dovish regime in the future has a much smaller effect on macroeconomic volatility: the volatilities of inflation and output are raised by only $17 \%$ and $3 \%$, respectively. In a number of other experiments, we find that the expectation effect in the hawkish regime remains small even if that regime is much less persistent (e.g., when $\left.q_{22}=0.7\right)$; on the other hand, the expectation effect in the dovish regime remains strong even if we set $q_{11}=0.98$ and $q_{22}=1.0$, the probabilities that might fit into some researchers' a priori belief.

IV.2. Endogenous propagation. Endogenous propagation mechanisms in our model play an important role in generating asymmetric expectation effects both in level and proportionally. A weaker propagation mechanism gives rise to less persistent dynamics of inflation and output and therefor smaller and less asymmetric expectation effects.

To see this point, we turn off endogenous propagation mechanisms by setting $b=$ $\iota=0$ and $\alpha=1$. To obtain closed form solutions, we also set $\rho_{r}=\phi_{y}=0$. It follows from Propositions 7 and 10 that the expectation effect, although asymmetric in level, 
is proportionally symmetric across regimes. ${ }^{7}$ More formally, we have

$$
\frac{\bar{v}_{\pi, 1}-v_{\pi, 1}}{\bar{v}_{\pi, 1}}=\frac{v_{\pi, 2}-\bar{v}_{\pi, 2}}{\bar{v}_{\pi, 2}} .
$$

We have experimented with several alternative parameterizations of the model in which we weaken the strategic complementarity in price setting by making the duration of price contracts shorter or the demand elasticity smaller. With weaker strategic complementarity, the slope of the Phillips curve measured by the parameter $\psi$ in (16) becomes steeper and the model's propagation mechanism becomes weaker. We find that, under these alternative parameterizations, the expectation effect becomes smaller and less asymmetric (see our working paper Liu, Waggoner, and Zha (2007) for more details).

These results underscore the important role of a strong propagation mechanism in asymmetric expectation effects, as the model with habit formation, dynamic indexation, and firm-specific factors produces more persistence in the dynamics of inflation and output and thus stronger asymmetry of expectation effects, as shown in Section IV.1.

IV.3. Less persistent shocks. Figures 1 and 2 show that the expectation effect is much larger for dynamic responses to demand and markup shocks than for responses to policy and technology shocks. Since demand and markup shocks are more persistent, one would like to know to what extent the asymmetry and the quantitative importance of expectation effects depend upon the persistence of these shocks. To address this question, we consider the model with i.i.d. shocks by setting the persistence parameters in all the shock processes to zero. We find that the expectation effect remains asymmetric. For instance, with our parameterizations and i.i.d. shocks, the expectation effect reduces inflation volatility by about $14 \%$ in the dovish regime; in contrast, in the hawkish regime, it amplifies inflation volatility by less than $5 \%$.

IV.4. Equilibrium determinacy. In our baseline parameterization, $\phi_{\pi, 1}<1$ violates the Taylor principle, implying local equilibrium indeterminacy if the dovish regime were to last indefinitely. As we have argued, the expectation effect arises not because one of the regimes would lead to indeterminacy in that regime; the asymmetric expectation effect exists as long as the two policy regimes differ in their aggressiveness against inflation fluctuations.

To make this point concrete, we set $\phi_{\pi, 1}=1.2$ and $\phi_{\pi, 2}=5$ (instead of 0.9 and 2.5 used in the baseline mdoel), while keeping all other parameters the same. With this variation, the interest rate rule satisfies the Taylor principle and the equilibrium is

\footnotetext{
${ }^{7}$ The same conclusion holds for the flexible-price model presented in Section III.1.
} 
unique in both regimes. Table 3 reports the volatility results. It is evident that although there is no issue of indeterminacy here, the expectation effect of regime switching remains quantitatively important under the dovish regime (especially for inflation), while it is much less important in the hawkish regime.

IV.5. Transition dynamics. In our discussion so far, we have focused on the expectation effects conditional on each policy regime. It is of interest to understand the expectation effects when policy regime actually switches. Suppose, for example, that dovish policy in the previous period $t-1$ switches to hawkish policy in the current period $t$. To examine the impact of this actual regime shift on dynamic responses to fundamental shocks and on expectation effects, we compare impulse responses under two different scenarios. In the first scenario, agents believe that such a regime shift is permanent (i.e., policy stays hawkish from period $t$ on). In the second scenario, agents understand that policy switches between the two regimes according to the Markov-switching process. In the absence of fundamental shocks, as we have shown in Proposition 5, a regime shift does not by itself affect equilibrium variables. What will be affected is dynamics responses to a particular shock that occurs at the same time when policy regime switches in the impact period $t$. Differences between the impulse responses under the two scenarios capture the expectation effects when policy actually shifts from one regime to the other.

Figure 3 displays impulse responses of inflation and output to a demand shock when policy regime switches in the impact period. ${ }^{8}$ The solid lines represent the responses when agents naively believe that the regime shift is permanent. The dashed lines represent the responses when agents understand that policy switches between the two regimes in subsequent periods according to the Markov-switching process. ${ }^{9}$ As shown in the figure, when policy switches from the hawkish to the dovish regime, the responses of inflation and output to a demand shock are substantially dampened when agents take into account possible future regime shifts; when policy switches from the dovish to the hawkish regime, the responses are slightly magnified (noticing the different scales) as agents take account of the probability of regime switches in the future. Thus, with the

\footnotetext{
${ }^{8}$ To conserve space, we focus on the impulse responses to a demand shock. Our conclusion does not change when we consider responses to a markup shock. Again, monetary policy and technology shocks do not seem to generate quantitatively important expectation effects.

${ }^{9}$ The impulse responses without expectation effects (the solid lines) are, by construction, identical to those in the baseline model. The responses with expectation effects (the dashed lines) are the means of 100000 simulations of inflation and output dynamics. These simulations are generated by randomly drawing both structural shocks and regimes.
} 
actual switch in policy regime taking place, the expectation effects remain asymmetric and can be quantitatively important. Compared to the impulse responses that are computed conditional on each regime (Figures 1 and 2), the responses of inflation and output are further dampened if the policy switches to the dovish regime and the responses are slightly amplified if the policy switches to the hawkish regime. These results are obtained based on the Markov transition probabilities $q_{11}=q_{22}=0.95$ so that a given regime lasts on average for 20 quarters. When policy regime switches more frequently (e.g, when the $q$ 's are 0.85 , implying an average duration of each regime of about 7 quarters), we find that the actual switch to the dovish regime generates larger expectation effects and the expectation effects become even more asymmetric (not reported here).

IV.6. Regime-dependent structural parameters. Some of the parameters in the model are not deep parameters and are thus likely to vary with policy regime. Examples include the Calvo sticky-price parameter $\eta$ and the inflation indexation parameter $\iota$. For comparison with the literature, we have so far treated these parameters as independent of policy regime. We now examine how expectation effects can be affected if these parameters are allowed to be regime-dependent. Specifically, we replace the constant parameters $\eta$ and $\iota$ by the regime-dependent parameters $\eta\left(s_{t-1}\right)$ and $\iota\left(s_{t-1}\right)$. For the same reason as in our baseline DSGE model, the steady-state equilibrium does not depend on policy regime. ${ }^{10}$

The log-linearized equilibrium conditions around the steady state are similar to those in the baseline model, except that the Phillips curve relation becomes more general and is given by

$$
\begin{aligned}
& \hat{\pi}_{t}-\gamma\left(s_{t-1}\right) \hat{\pi}_{t-1}=\beta \psi_{1}\left(s_{t}, s_{t-1}\right) \mathrm{E}_{t}\left(\hat{\pi}_{t+1}-\gamma\left(s_{t}\right) \hat{\pi}_{t}\right) \\
& \quad+\psi_{2}\left(s_{t-1}\right)\left[\frac{\xi+1}{\alpha} \hat{y}_{t}+\frac{b}{\lambda-b}\left(\hat{y}_{t}-\hat{y}_{t-1}+\hat{\nu}_{t}\right)\right]+\psi_{2}\left(s_{t-1}\right) \hat{\mu}_{w t}
\end{aligned}
$$

where

$\psi_{1}\left(s_{t}, s_{t-1}\right)=\frac{\bar{\eta}}{\eta\left(s_{t-1}\right)} \frac{1-\eta\left(s_{t-1}\right)}{1-\eta\left(s_{t}\right)}, \quad \psi_{2}\left(s_{t-1}\right)=\frac{(1-\beta \bar{\eta})\left(1-\eta\left(s_{t-1}\right)\right)}{\eta\left(s_{t-1}\right)} \frac{1}{1+\theta_{p}(1-\alpha) / \alpha}$.

\footnotetext{
${ }^{10}$ This result holds because the regime-dependent parameters affect nominal rigidities only and have no effects on real variables in the steady state. If we allow for regime-dependence of some parameters that represent real frictions (such as the habit persistence parameter), a different approach is needed to obtain the deterministic steady state. This issue is important enough to deserve a separate investigation in future research.
} 
Note that $\bar{\eta}$ is the ergodic mean of the random variable $\eta\left(s_{t}\right){ }^{11}$

We assume that in the dovish regime firms adjust prices more frequently and, for those who cannot re-optimize pricing, they index to past inflation more heavily than in the hawkish regime. This assumption seems plausible as inflation is likely higher and more volatile in the dovish regime than in the hawkish regime. In particular, we set $\eta(1)=0.66$ and $\eta(2)=0.75$, so that price contracts last on average for 3 quarters under the dovish regime and 4 quarters under the hawkish regime; we set $\iota(1)=1$ and $\iota(2)=0$, so that there is full indexation under the dovish regime and no indexation under the hawkish regime. ${ }^{12}$ All other parameter values remain the same as in the baseline model.

Figure 4 displays impulse responses of inflation and output to a demand shock. The solid lines represent the impulse responses without expectation effects and the dashed lines represent those with expectation effects. The figure shows that, as in the baseline model, expectation effects help stabilize inflation and output under the dovish regime and amplify fluctuations under the hawkish regime. The expectation effects are asymmetric because the stabilizing effect is larger than the amplifying effect. Thus, allowing the price stickiness parameter and the inflation indexation parameter to vary with policy regime supports our general conclusion about existence and asymmetry of the expectation effects. A comparison of Figures 1 and 2 indicates that a generalization of these parameter values strengthens the quantitative importance and asymmetry of expectation effects obtained for our baseline model.

\section{Conclusion}

We have studied two canonical DSGE models with monetary policy following a Markov-switching process between a dovish regime and a hawkish regime, where monetary policy in the hawkish regime responds to inflation more strongly than in the dovish regime. We have shown, in theory and through simulations, that (1) because inflation expectations can be influenced, in a nonlinear way, either by hawkish policy itself or through the expectation of a switch to this policy in the future, the expectation effect is asymmetric across regimes; (2) in the dovish regime, the expectation effect

\footnotetext{
${ }^{11}$ For derivations of this equation and other details about the model's optimizing conditions when $\eta$ and $\iota$ are regime-dependent, see the earlier version of this paper (Liu, Waggoner, and Zha (2007)).

${ }^{12}$ Ideally, these regime-switching parameters should be estimated along with the policy parameters and other deep parameters in the DSGE model. Although estimation of the model parameters is beyond the scope of the paper, the ad hoc parameter values that we use here help illustrate the model's mechanism.
} 
can be quantitatively important, a theoretical result consistent with the evidence that changes in policy regime may not be a main source of substantial volatility reductions observed in macroeconomic time series; and (3) in the hawkish regime, on the other hand, the expectation effect of a change in future policy is quantitatively less important. The asymmetry of expectation effects across the two policy regimes offers one plausible explanation of why the post-1982 monetary policy in the United States has been successful in reducing the volatility of both inflation and output, despite agents' disbelief that hawkish policy will prevail indefinitely (Goodfriend and King, 2005).

Our finding that the expectation effect can be quantitatively important provides a clear argument for continuing the existing line of research on Markov-switching DSGE models that explicitly incorporate the possibility of regime shifts in agent's information set. A more ambitious task is to estimate a regime-switching DSGE model with a long data sample that covers different policy regimes. Some progress has been made in this direction (Liu, Waggoner, and Zha, 2008). We believe that this line of research can be both important and fruitful.

\section{Appendix A. The Sticky Price Model}

The model economy is populated by a continuum of infinitely-lived identical households, each endowed with a unit of labor time; and a continuum of firms, each producing a differentiated product using labor as the input. The representative household consumes a composite good, which is produced in a perfectly competitive aggregation sector using all differentiated products as inputs. In each period, rational agents observe the realization of shocks and the monetary policy regime before making optimizing decisions.

The representative household's utility function is given by

$$
\mathrm{E} \sum_{t=0}^{\infty} \beta^{t} A_{t}\left\{\log \left(C_{t}-b \bar{C}_{t-1}\right)-\frac{\Psi}{1+\xi} L_{t}^{1+\xi}\right\}
$$

subject to the sequence of budget constraints

$$
\bar{P}_{t} C_{t}+\mathrm{E}_{t} D_{t, t+1} B_{t+1} \leq W_{t} L_{t}+B_{t}+\Pi_{t}
$$

for $t \geq 0$. In the expressions above, $C_{t}$ denotes consumption, $\bar{C}_{t-1}$ is the lagged aggregate consumption, $b \geq 0$ measures the importance of habit formation, $L_{t}$ denotes labor, $A_{t}$ denotes the preference shock, $B_{t+1}$ denotes a state-contingent nominal bond that represents a claim to one dollar in a particular event in period $t+1$ and costs $D_{t, t+1}$ dollars in period $t, \bar{P}_{t}$ denotes the price level, $W_{t}$ denotes the nominal wage, and $\Pi_{t}$ denotes the profit share. The term $\mathrm{E}$ is an expectation operator, the parameter 
$\beta \in(0,1)$ is a subjective discount factor, $\xi$ is the inverse Frisch elasticity of labor supply, and $\Psi$ is the relative weight of leisure in the utility function. The preference shock $A_{t}$ follows the stochastic process described in (1).

The final consumption good is produced in the perfectly competitive aggregation sector using differentiated intermediate goods as inputs, with the Dixit-Stiglitz aggregation technology

$$
C_{t}=\left[\int_{0}^{1} Y_{t}(j)^{\frac{\theta_{t}-1}{\theta_{t}}} d j\right]^{\frac{\theta_{t}}{\theta_{t}-1}},
$$

where $Y_{t}(j)$ denotes the type- $j$ intermediate good and $\theta_{t}>1$ is the elasticity of substitution between the differentiated intermediate goods. The price markup is measured by $\mu_{t}=\theta_{t} /\left(\theta_{t}-1\right)$, which follows the stationary stochastic process described in (18).

Cost-minimizing implies that

$$
Y_{t}^{d}(j)=\left(\frac{P_{t}(j)}{\bar{P}_{t}}\right)^{-\theta_{t}} C_{t} .
$$

Zero-profit implies that the price index $\bar{P}_{t}$ is related to the prices $P_{t}(j)$ of differentiated goods through

$$
\bar{P}_{t}=\left[\int_{0}^{1} P_{t}(j)^{1-\theta_{t}}\right]^{\frac{1}{1-\theta_{t}}} .
$$

The production function for firm $j \in[0,1]$ is given by

$$
Y_{t}(j)=Z_{t} L_{t}(j)^{\alpha}
$$

Following Chari, Kehoe, and McGrattan (2000), we assume that firms' production requires both labor and firm-specific factors (such as land or capital stock that is inelastically supplied) so that $\alpha \in(0,1]$. The technology shock $Z_{t}$ follows the stochastic process

$$
Z_{t}=Z_{t-1} \lambda \nu_{t}
$$

where $\lambda$ measures the deterministic trend of $Z_{t}$ and $\nu_{t}$ is a stochastic component of $Z_{t}$. The stochastic component follows the stationary process described in (17).

Firms in the intermediate good sector are price-takers in the input market and monopolistic competitors in the product markets. They set prices for their differentiated products in a staggered fashion. Following Calvo (1983), we assume that in each period, each firm receives a random i.i.d. signal that enables the firm to set a new price. The probability that a firm cannot adjust its price is $\eta$. By the law of large numbers, a fraction $1-\eta$ of firms in a given period can optimize their pricing decisions while the remaining firms cannot. Following Woodford (2003), CEE (2005), and Smets and Wouters (2007), we allow a fraction $\iota$ of firms that cannot re-optimize their pricing 
decisions to index their prices to the overall price inflation realized in the past period. If the firm $j$ cannot set a new price, its price is automatically updated according to

$$
P_{t}(j)=\pi_{t-1}^{\iota} \pi^{1-\iota} P_{t-1}(j),
$$

where $\pi_{t}=\bar{P}_{t} / \bar{P}_{t-1}$ is the inflation rate between $t-1$ and $t, \pi$ is the steady-state inflation rate, and $\iota$ measures the degree of indexation. If the firm $j$ can set a new price, it chooses $P_{t}(j)$ to maximize its expected discounted dividend flows given by

$$
\mathrm{E}_{t} \sum_{i=0}^{\infty} \eta^{i} D_{t, t+i}\left[P_{t}(j) \chi_{t, t+i} Y_{t+i}^{d}(j)-W_{t+i}(j)\left(\frac{Y_{t+i}^{d}(j)}{Z_{t+1}}\right)^{1 / \alpha}\right]
$$

subject to the demand schedule (A4). The term $D_{t, t+i}$ is the period- $t$ present value of a dollar in a future state in period $t+i$ and the term $\chi_{t, t+i}$ comes from the price-updating rule (A8) and is given by

$$
\chi_{t, t+i}= \begin{cases}\pi_{t+i-1}^{\iota} \pi_{t+i-2}^{\iota} \cdots \pi_{t}^{\iota} \pi^{(1-\iota) i} & \text { if } i \geq 1 \\ 1 & \text { if } i=0\end{cases}
$$

The monetary authority follows the interest-rate rule described in (14), where the coefficients depend on policy regime and there is an i.i.d. monetary policy shock $\varepsilon_{r t}$. All the structural shocks $\varepsilon_{r t}, \varepsilon_{a t}, \varepsilon_{\mu t}$, and $\varepsilon_{\nu t}$ are assumed to be mutually independent.

Given monetary policy, an equilibrium in this economy consists of prices and allocations such that (i) taking prices as given, the representative household's allocations solve its utility maximizing problem; (ii) taking all prices but its own as given, each firm's allocation and price solve its profit maximizing problem; (iii) markets clear for bond, money balances, labor, and composite final goods.

The first-order necessary conditions for the household's utility maximization problem result in the labor supply equation

$$
\frac{W_{t}}{\bar{P}_{t}}=\Psi\left(C_{t}-b C_{t-1}\right) L_{t}^{\xi}
$$

and the intertemporal Euler equation

$$
1=\beta \mathrm{E}_{t} \frac{A_{t+1}}{A_{t}} \frac{C_{t}-b C_{t-1}}{C_{t+1}-b C_{t}} \frac{\bar{P}_{t}}{\bar{P}_{t+1}} R_{t} .
$$

The firms' optimal pricing decision implies that

$$
\mathrm{E}_{t} \sum_{i=0}^{\infty} \eta^{i} D_{t, t+i} Y_{t+i}^{d}(j) \frac{1}{\mu_{t+i}-1}\left[\mu_{t+i} \Phi_{t+i}(j)-P_{t}(j) \chi_{t, t+i}\right]=0
$$

where $\Phi_{t+i}(j)$ denotes the marginal cost given by

$$
\Phi_{t+i}(j)=\frac{1}{\alpha} \frac{W_{t+i}}{Z_{t+i}}\left(\frac{Y_{t+i}(j)^{d}}{Z_{t+i}}\right)^{1 / \alpha-1}
$$


Because the productivity shock $Z_{t}$ in the model contains a trend, we focus on a stationary equilibrium (i.e., the balanced growth path). In the stationary equilibrium, aggregate output, consumption, and the real wage grow at the same rate as does the productivity, while hours do not grow. To induce stationarity, we divide each of the growing variables by $Z_{t}$ and denote the resulting stationary counterpart of the variable $X_{t}$ by $\tilde{X}_{t}=X_{t} / Z_{t}$.

A.1. The Steady State Equilibrium. We now derive the steady-state equilibrium solution and prove the result in Proposition 5. In the steady state, all the structural shocks are turned off. The steady-state equilibrium can be summarized by the solution to the four equilibrium conditions: the optimal pricing decision (A13), the labor supply equation (A11), the intertemporal Euler equation (A12), and the Taylor rule (14).

The optimal pricing equation (A13) implies that, in the steady state, the real marginal cost is equal to the inverse of the markup:

$$
\frac{1}{\mu_{p}}=\frac{1}{\alpha} \tilde{W} \tilde{Y}^{1 / \alpha-1}
$$

where $\tilde{W}=\frac{W}{P Z}$ denotes the transformed real wage and $\tilde{Y}=\frac{Y}{Z}$ denotes transformed output.

The labor supply equation (A11) implies that the real wage in the steady state equals the marginal rate of substitution (MRS):

$$
\tilde{W}=\Psi \tilde{Y}^{\xi}\left(\tilde{Y}-\frac{b}{\lambda} \tilde{Y}\right)
$$

where we have used the goods market clearing condition that $\tilde{C}=\tilde{Y}$ and the aggregate production function that $L=\tilde{Y}$.

The household's optimal intertemporal decision (A12) implies that, in the steadystate equilibrium, we have

$$
\frac{R}{\pi}=\frac{\lambda}{\beta}
$$

The Taylor rule in the steady-state equilibrium implies that

$$
R=\kappa(s)\left(\frac{\pi}{\pi^{*}}\right)^{\phi_{\pi}(s)} \tilde{Y}^{\phi_{y}(s)} .
$$

The steady-state equilibrium features the classical dichotomy. The real variables $\tilde{Y}$ and $\tilde{W}$ are determined by Equations (A15) and (A16). Upon obtaining the solution for $\tilde{Y}$, we can use the production function and the goods market clearing condition to get the steady-state hours and consumption: $L=\tilde{C}=\tilde{Y}$. Evidently, the steady-state values of the real variables are independent of policy regime. The nominal variables $\pi$ and $R$, on the other hand, can be solved from Equations (A17) and (A18) once the 
real variables are determined. We claim in Proposition 5 that, by appropriate choice of the scale parameter $\kappa(s)$, the monetary authority will be able to achieve its inflation target in the steady state so that $\pi=\pi^{*}$. Then, Equation (A17) gives the solution for the steady-state nominal interest rate: $R=\frac{\lambda}{\beta} \pi^{*}$. Thus, the steady-state values of the nominal variables $\pi$ and $R$ are independent of policy regime either. The restriction on the scale parameter $\kappa(s)$ described in (15) comes from (A18). This proves Proposition 5 .

\section{Appendix B. Proofs of Other Propositions}

B.1. Proof of Proposition 1. We solve the model (8) by the method of undetermined coefficients. Given the solution form $\hat{\pi}_{t}=\alpha_{s_{t}} \hat{a}_{t}$ for $s_{t} \in\{1,2\}$, (8) implies that

$$
\begin{aligned}
& \phi_{1} \alpha_{1} \hat{a}_{t}=q_{11} \alpha_{1} \rho_{a} \hat{a}_{t}+q_{21} \alpha_{2} \rho_{a} \hat{a}_{t}+\gamma\left(1-\rho_{a}\right) \hat{a}_{t}, \\
& \phi_{2} \alpha_{2} \hat{a}_{t}=q_{12} \alpha_{1} \rho_{a} \hat{a}_{t}+q_{22} \alpha_{2} \rho_{a} \hat{a}_{t}+\gamma\left(1-\rho_{a}\right) \hat{a}_{t},
\end{aligned}
$$

where we have used the relation $\mathrm{E}_{t} \hat{a}_{t+1}=\rho_{a} \hat{a}_{t}$. Matching the coefficients on $\hat{a}_{t}$, we obtain

$$
\begin{aligned}
& \phi_{1} \alpha_{1}=q_{11} \alpha_{1} \rho_{a}+q_{21} \alpha_{2} \rho_{a}+\gamma\left(1-\rho_{a}\right), \\
& \phi_{2} \alpha_{2}=q_{12} \alpha_{1} \rho_{a}+q_{22} \alpha_{2} \rho_{a}+\gamma\left(1-\rho_{a}\right) .
\end{aligned}
$$

It follows that the solution $\left[\alpha_{1}, \alpha_{2}\right]^{\prime}$ is given by the expression in (9).

B.2. Proof of Proposition 2. Given the solution form $\hat{\pi}_{t}=\bar{\alpha}_{j} \hat{a}_{t}$, we have $\mathrm{E}_{t} \hat{\pi}_{t+1}=$ $\bar{\alpha}_{j} \rho_{a} \hat{a}_{t}$ and (11) is a result from matching the coefficients of $\hat{a}_{t}$.

B.3. Proof of Proposition 3. Denote by $\alpha=\left[\alpha_{1}, \alpha_{2}\right]^{\prime}$ and $C=\gamma\left(1-\rho_{a}\right)[1,1]^{\prime}$. The MSV solution in (9) can be rewritten as

$$
\alpha=A^{-1} C
$$

Since the assumption that $\phi_{2}>\phi_{1}>\rho_{a}$ implies that $A$ is positive definite, $\alpha_{1}$ and $\alpha_{2}$ are both positive.

To establish the first inequality in (12), we use the relation $q_{11}=1-q_{21}$ and differentiate (A19) and (A20) with respect to $q_{21}$ to obtain

$$
\begin{aligned}
\phi_{1} \frac{\partial \alpha_{1}}{\partial q_{21}} & =q_{11} \rho_{a} \frac{\partial \alpha_{1}}{\partial q_{21}}+\left(\alpha_{2}-\alpha_{1}\right) \rho_{a}+q_{21} \rho_{a} \frac{\partial \alpha_{2}}{\partial q_{21}} \\
\phi_{2} \frac{\partial \alpha_{2}}{\partial q_{21}} & =q_{12} \rho_{a} \frac{\partial \alpha_{1}}{\partial q_{21}}+q_{22} \rho_{a} \frac{\partial \alpha_{2}}{\partial q_{21}} .
\end{aligned}
$$


With appropriate substitutions, we get

$$
\frac{\partial \alpha_{1}}{\partial q_{21}}=\frac{\gamma \rho_{a}\left(1-\rho_{a}\right)\left(\phi_{2}-q_{22} \rho_{a}\right)\left(\phi_{1}-\phi_{2}\right)}{\operatorname{det}(A)^{2}}<0,
$$

where the inequality follows from the assumption that $\phi_{1}<1<\phi_{2}$. Similarly, we can show that

$$
\frac{\partial \alpha_{2}}{\partial q_{12}}=\frac{\gamma \rho_{a}\left(1-\rho_{a}\right)\left(\phi_{1}-q_{11} \rho_{a}\right)\left(\phi_{2}-\phi_{1}\right)}{\operatorname{det}(A)^{2}} .
$$

The desired inequality $\frac{\partial \alpha_{2}}{\partial q_{12}}>0$ then follows from the assumption $\phi_{2}>\phi_{1}>\rho_{a}$.

B.4. Proof of Proposition 4. The solution for the regime-switching model (9) can be rewritten as

$$
\alpha_{j}=\frac{\left(q_{i j} \rho_{a}+\phi_{i}-q_{i i} \rho_{a}\right) \gamma\left(1-\rho_{a}\right)}{\operatorname{det}(A)}, \quad i j \in\{1,2\}, \quad i \neq j .
$$

Using the solution for the constant regime model in (11), we have

$$
\begin{aligned}
\frac{\bar{\alpha}_{1}-\alpha_{1}}{\alpha_{2}-\bar{\alpha}_{2}} & =\frac{\frac{1}{\phi_{1}-\rho_{a}}-\frac{q_{21} \rho_{a}+\phi_{2}-q_{22} \rho_{a}}{\operatorname{det}(A)}}{\frac{q_{12} \rho_{a}+\phi_{1}-q_{11} \rho_{a}}{\operatorname{det}(A)}-\frac{1}{\phi_{2}-\rho_{a}}} \\
& =\frac{\phi_{2}-\rho_{a}}{\phi_{1}-\rho_{a}} \frac{\operatorname{det}(A)-\left(\phi_{1}-\rho_{a}\right)\left(q_{21} \rho_{a}+\phi_{2}-q_{22} \rho_{a}\right)}{\left(\phi_{2}-\rho_{a}\right)\left(q_{12} \rho_{a}+\phi_{1}-q_{11} \rho_{a}\right)-\operatorname{det}(A)} \\
& =\frac{\phi_{2}-\rho_{a}}{\phi_{1}-\rho_{a}} \frac{1-q_{11}}{1-q_{22}} .
\end{aligned}
$$

The desired inequality in (13) follows from the assumptions that $q_{11}=q_{22}$ and $\phi_{2}>\phi_{1}$.

B.5. Proof of Proposition 6. We solve the model (24) by using the method of undetermined coefficients. The conjectured solution implies that

$\beta \rho_{a}^{2}\left[\gamma_{1}\left(q_{11}^{2}+q_{21} q_{12}\right)+\gamma_{2} q_{21}\left(q_{11}+q_{22}\right)\right]-\rho_{a}(1+\beta+\kappa)\left(\gamma_{1} q_{11}+\gamma_{2} q_{21}\right)+\left(1+\kappa \phi_{1}\right) \gamma_{1}=\kappa\left(1-\rho_{a}\right)$

$\beta \rho_{a}^{2}\left[\gamma_{2}\left(q_{22}^{2}+q_{21} q_{12}\right)+\gamma_{1} q_{12}\left(q_{11}+q_{22}\right)\right]-\rho_{a}(1+\beta+\kappa)\left(\gamma_{2} q_{22}+\gamma_{1} q_{12}\right)+\left(1+\kappa \phi_{2}\right) \gamma_{2}=\kappa\left(1-\rho_{a}\right)$,

where we have used the Markov transition property of the regime switching process and the $\mathrm{AR}(1)$ property of the shock and we have also matched the coefficients for $\hat{a}_{t}$ in each equation. Collecting terms, we obtain the solution (25).

B.6. Proof of Proposition 8. The MSV solution (25) can be written in a compact form $A \gamma=B$, where $\gamma=\left[\gamma_{1}, \gamma_{2}\right]^{\prime}$ and $B=[1,1]^{\prime} \kappa\left(1-\rho_{a}\right)$. Total differentiation with respect to $q_{21}$, we obtain

$$
\frac{\partial A}{\partial q_{21}} \gamma+A \frac{\partial \gamma}{\partial q_{21}}=0
$$


where

$$
\begin{aligned}
\frac{\partial A}{\partial q_{21}} \gamma & =\left(\gamma_{2}-\gamma_{1}\right)\left[\begin{array}{c}
\rho_{a}\left[\beta \rho_{a}\left(2 q_{11}+q_{22}-1\right)-(1+\beta+\kappa)\right] \\
\beta \rho_{a}^{2} q_{12}
\end{array}\right] \\
& =\frac{\kappa^{2}\left(1-\rho_{a}\right)\left(\phi_{1}-\phi_{2}\right)}{\operatorname{det}(A)}\left[\begin{array}{c}
\rho_{a}\left[\beta \rho_{a}\left(2 q_{11}+q_{22}-1\right)-(1+\beta+\kappa)\right] \\
\beta \rho_{a}^{2} q_{12}
\end{array}\right] .
\end{aligned}
$$

With some further algebra, we obtain

$$
\begin{aligned}
& \frac{\partial \gamma_{1}}{\partial q_{21}}=\frac{\kappa^{2}\left(1-\rho_{a}\right)\left(\phi_{2}-\phi_{1}\right)}{\operatorname{det}(A)^{2}}\left\{-\left(\beta \rho_{a}^{2}\right)^{2}\left(1-q_{11}\right)^{2}\left(1-q_{22}\right)+\right. \\
& \left.\quad\left[\beta\left(\rho_{a} q_{22}\right)^{2}-(1+\beta+\kappa) \rho_{a} q_{22}+1+\kappa \phi_{2}\right]\left[\beta \rho_{a}^{2}\left(q_{11}+q_{22}-q_{21}\right)-\rho_{a}(1+\beta+\kappa)\right]\right\}<0 .
\end{aligned}
$$

where the last inequality follows since $\phi_{2}>\phi_{1}$ and, given that $\phi_{2}>1$, the term in the first square bracket is positive (while the term in the second square bracket is clearly negative).

Following similar steps, we obtain

$$
\begin{aligned}
& \frac{\partial \gamma_{2}}{\partial q_{12}}=\frac{\kappa^{2}\left(1-\rho_{a}\right)\left(\phi_{1}-\phi_{2}\right)}{\operatorname{det}(A)^{2}}\left\{-\left(\beta \rho_{a}^{2}\right)^{2}\left(1-q_{22}\right)^{2}\left(1-q_{11}\right)+\right. \\
& \left.\quad\left[\beta\left(\rho_{a} q_{11}\right)^{2}-(1+\beta+\kappa) \rho_{a} q_{11}+1+\kappa \phi_{1}\right]\left[\beta \rho_{a}^{2}\left(q_{11}+q_{22}-q_{12}\right)-\rho_{a}(1+\beta+\kappa)\right]\right\} .
\end{aligned}
$$

Since $\phi_{1}<\phi_{2}$ and the term in the last square bracket is negative, to show that $\frac{\partial \gamma_{2}}{\partial q_{12}}>0$, it is sufficient to establish that $\beta\left(\rho_{a} q_{11}\right)^{2}-(1+\beta+\kappa) \rho_{a} q_{11}+1+\kappa \phi_{1}>0$. The desired inequality follows from the assumption in Proposition 7 that $\kappa\left(\phi_{1}-\rho_{a}\right)>$ $-\left(1-\rho_{a}\right)\left(1-\beta \rho_{a}\right)$ (so that $\left.\bar{\gamma}_{1}>0\right)$. 
TABLE 1. Constant parameters

\begin{tabular}{|c|c|c|c|}
\hline Preference & $\beta=0.9952$ & $\xi=2$ & $b=0.75$ \\
\hline Technology & $\alpha=0.7$ & $\lambda=1.005$ & $\theta=10$ \\
\hline Price setting & $\eta=0.66$ & $\iota=1$ & \\
\hline Policy rule & $\rho_{r}=0.55$ & $\phi_{y}=0.5$ & \\
\hline \multicolumn{4}{|l|}{ Aggregate Shocks } \\
\hline Persistence & $\rho_{a}=0.9$ & $\rho_{\mu}=0.9$ & $\rho_{\nu}=0$ \\
\hline Standard dev. & $\sigma_{r}=0.1$ & $\sigma_{a}=0.1$ & $\sigma_{\mu}=0.1 \quad \sigma_{\nu}=0.1$ \\
\hline Regime transition prob. & $q_{11}=0.95$ & $q_{22}=0.95$ & \\
\hline
\end{tabular}

TABLE 2. Effects of regime shifts on macroeconomic volatility ( baseline: $\phi_{\pi, 1}=0.9$ and $\left.\phi_{\pi, 2}=2.5\right)$

\begin{tabular}{|c|c|c|}
\hline \multicolumn{3}{|c|}{ A. Ignoring Expectation Effects } \\
\hline Regime & Inflation & Output \\
\hline Dovish & 0.334 & 0.139 \\
\hline Hawkish & 0.029 & 0.089 \\
\hline \multicolumn{3}{|c|}{ B. Accounting for Expectation Effects } \\
\hline Regime & Inflation & Output \\
\hline Dovish & 0.134 & 0.105 \\
\hline Hawkish & 0.034 & 0.092 \\
\hline
\end{tabular}

TABLE 3. Effects of regime shifts on macroeconomic volatility ( determinacy: $\phi_{\pi, 1}=1.2$ and $\phi_{\pi, 2}=5$ )

\begin{tabular}{|c|c|c|}
\hline \multicolumn{3}{|c|}{ A. Ignoring Expectation Effects } \\
\hline Regime & Inflation & Output \\
\hline Dovish & 0.085 & 0.099 \\
\hline Hawkish & 0.016 & 0.084 \\
\hline \multicolumn{3}{|c|}{ B. Accounting for Expectation Effect } \\
\hline Regime & Inflation & Output \\
\hline Dovish & 0.062 & 0.096 \\
\hline Hawkish & 0.017 & 0.085 \\
\hline
\end{tabular}



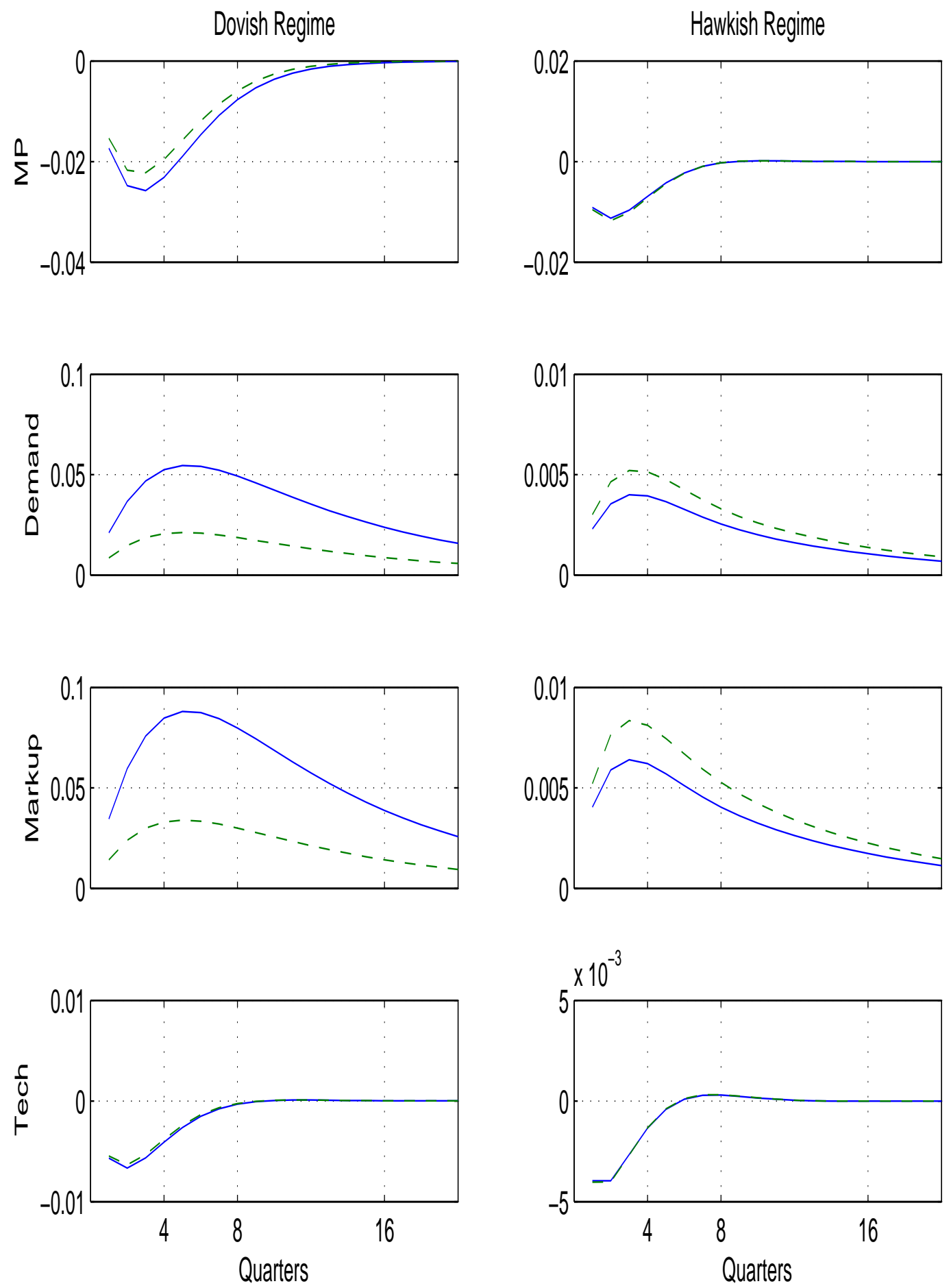

FIGURE 1. Impulse responses of inflation to various shocks in the baseline model. The solid lines represent the responses without expectation effects. The dashed lines represent the responses with expectation effects. 

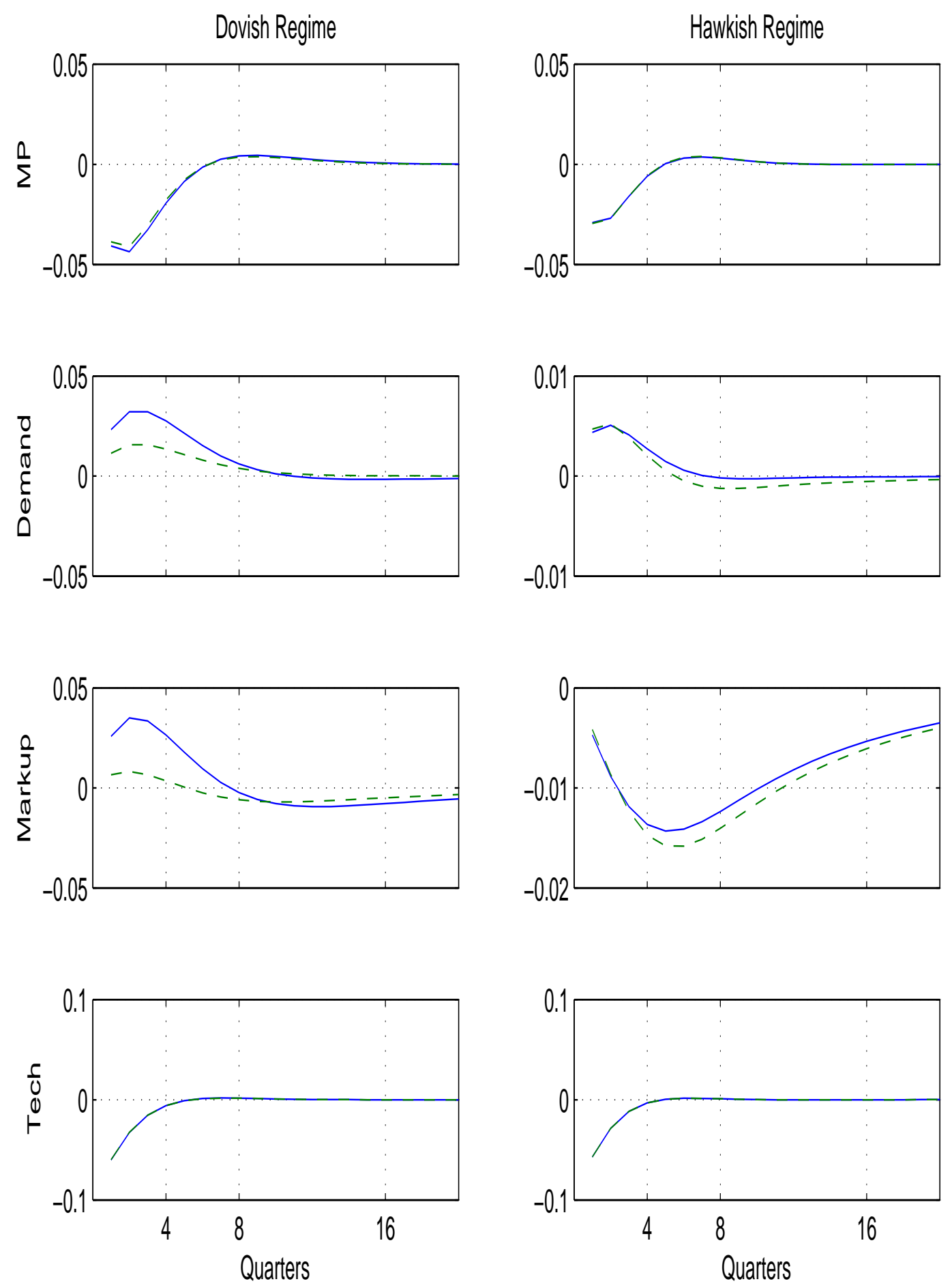

FIGURE 2. Impulse responses of output to various shocks in the baseline model. The solid lines represent the responses without expectation effects. The dashed lines represent the responses with expectation effects. 

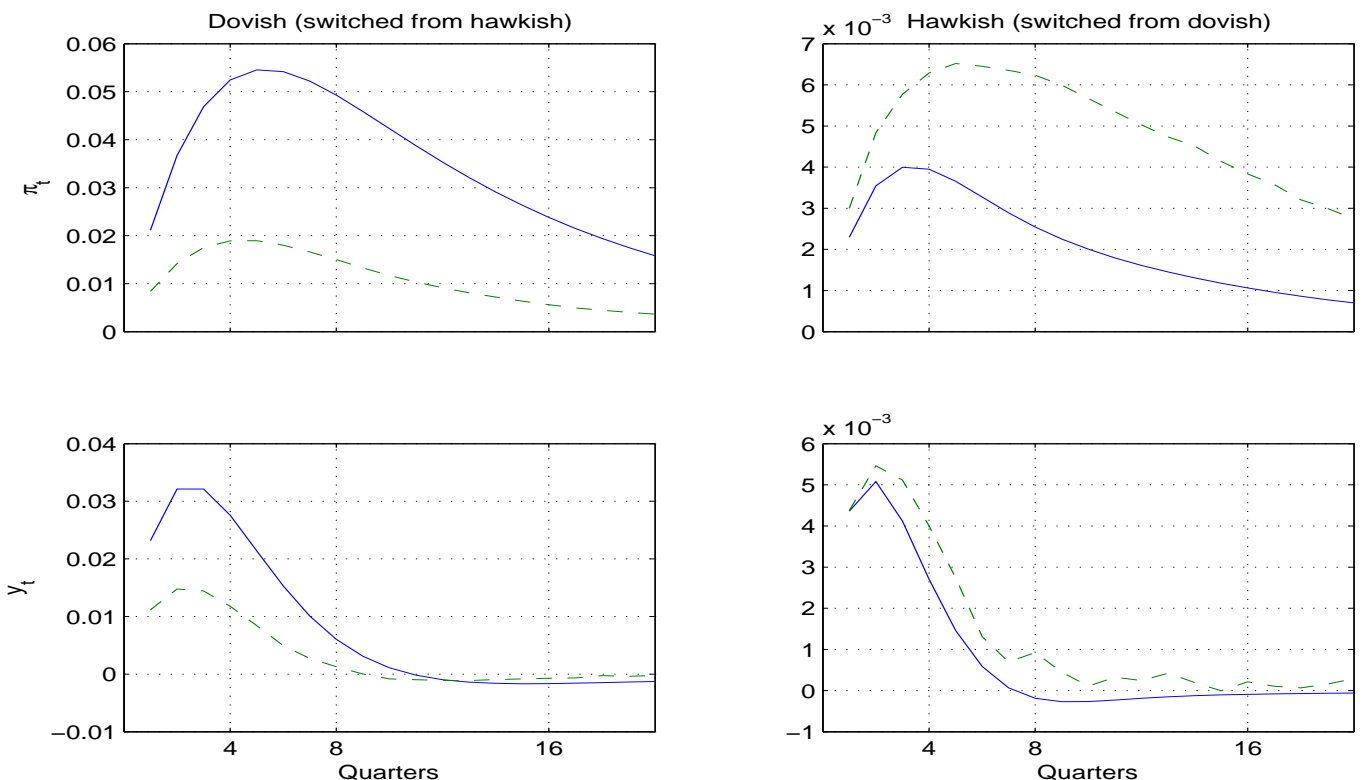

FiguRE 3. Impulse responses of inflation and output to a demand shock in the baseline model when policy actually switches regime in the impact period. The solid lines represent the responses without expectation effects. The dashed lines represent the responses with expectation effects.
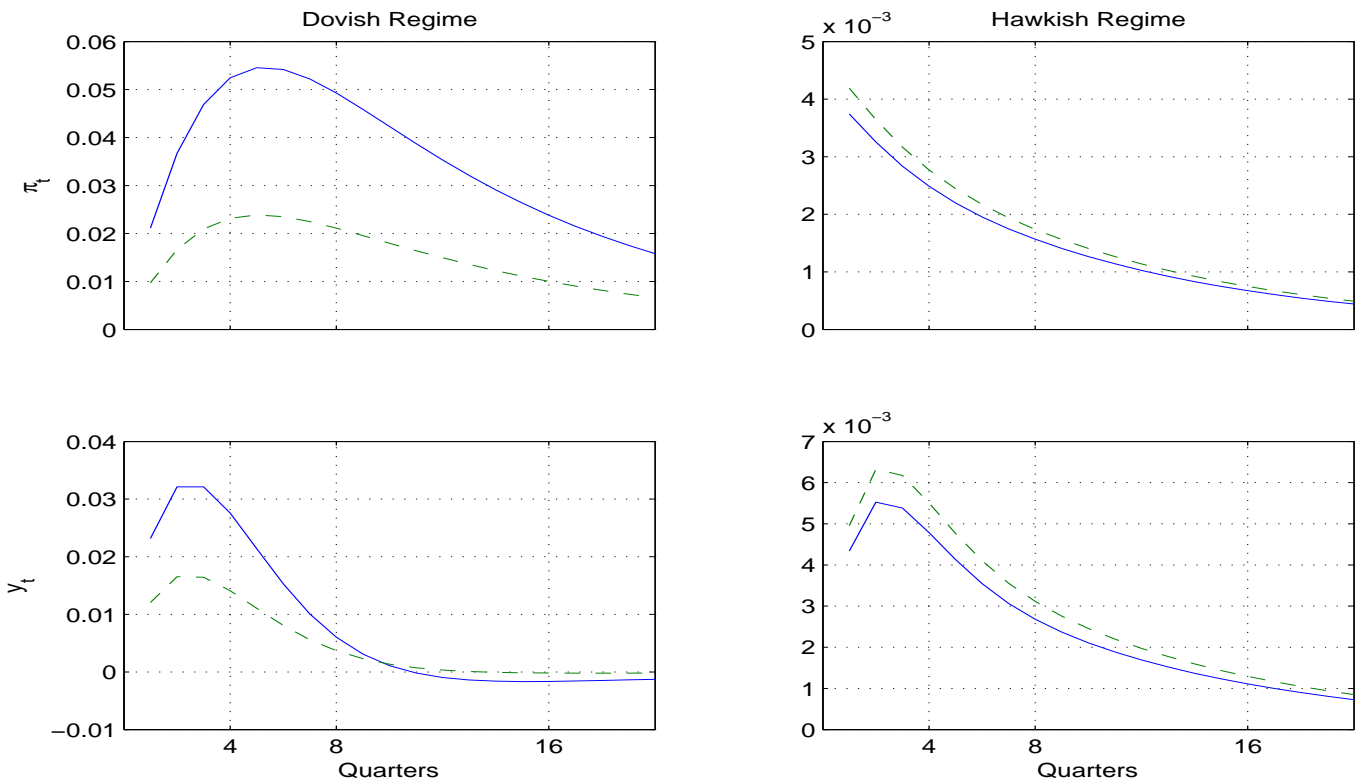

FiguRE 4. Impulse responses of inflation and output to a demand shock in the model with regime-dependent nominal rigidity parameters. The solid lines represent the responses without expectation effects. The dashed lines represent the responses with expectation effects. 


\section{REFERENCES}

Andolfatto, D., And P. Gomme (2003): "Monetary Policy Regimes and Beliefs," International Economic Review, 44(1), 1-30.

Barro, R. J. (1984): "Discussion on 'Autoregressions, Expectations, and Advice'," American Economic Review, 74(2), 416-417.

Basu, S., And J. G. Fernald (2002): "Aggregate Productivity and Aggregate Technology," European Economic Review, 46(2), 963-991.

Bernanke, B. S., and F. S. Mishkin (1997): "Inflation Targeting: A New Framework for Monetary Policy," Journal of Economic Perspectives, 11(2), 97-116.

Boivin, J., And M. Giannoni (2006): "Has Monetary Policy Become More Effective?," Review of Economics and Statistics, 88(3), 445-462.

Boldrin, M., L. J. Christiano, and J. D. Fisher (2001): "Habit Persistence, Asset Returns, and the Business Cycle," American Economic Review, 91(1), 149166.

Calvo, G. (1983): "Staggered Prices in a Utility-Maximizing Framework," Journal of Monetary Economics, 12(3), 383-398.

Cecchetti, S. G., P. Hooper, B. C. Kasman, K. L. Schoenholtz, and M. W. Watson (2007): "Understanding the Evolving Inflation Process," U.S. Monetary Policy Forum 2007, University of Chicago and Brandeis University.

Chari, V., P. J. Kehoe, and E. R. McGrattan (2000): "Sticky Price Models of the Business Cycle: Can the Contract Multiplier Solve the Persistence Problem?," Econometrica, 68(5), 1151-1180.

Christiano, L., M. Eichenbaum, and C. Evans (2005): "Nominal Rigidities and the Dynamic Effects of a Shock to Monetary Policy," Journal of Political Economy, $113(1), 1-45$.

Clarida, R., J. Galí, and M. Gertler (2000): "Monetary Policy Rules and Macroeconomic Stability: Evidence and Some Theory," Quarterly Journal of Economics, 115(1), 147-180.

Cooley, T. F., S. F. LeRoy, and N. Raymon (1984): "Econometric Policy Evaluation: Note," American Economic Review, 74(3), 467-470.

Davig, T., And E. M. Leeper (2007): "Generalizing the Taylor Principle," American Economic Review, 97(3), 607-635.

Del Negro, M., F. Schorfheide, F. Smets, and R. Wouters (2007): "On the Fit and Forecasting Performance of New Keynesian Models," Journal of Business and Economic Statistics, 25(2), 123-143. 
ERCEG, C. J., And A. T. Levin (2003): "Imperfect Credibility andn Inflation Persistence," Journal of Monetary Economics, 50, 915-944.

Farmer, R. E., D. F. Waggoner, and T. Zha (2006): "Minimal State Variable Solutions to Markov-Switching Rational Expectations Models," Manuscript, UCLA and Federal Reserve Bank of Atlanta.

(2007): "Understanding the New-Keynesian Model When Monetary Policy Switches Regimes," NBER Working Paper 12965.

(2008): "Generalizing the Taylor Principle: Comment," Manuscript, UCLA and Federal Reserve Bank of Atlanta.

Galí, J., And M. Gertler (1999): "Inflation Dynamics: A Structural Econometric Analysis," Journal of Monetary Economics, 44(2), 195-222.

Goodfriend, M., And R. G. King (2005): "The Incredible Volcker Disinflation," Journal of Monetary Economics, 52(5), 981-1015.

Ireland, P. N. (2004): "Technology Shocks in the New Keynesian Model," Review of Economics and Statistics, 86(4), 923-936.

LeEper, E. M., AND T. Zha (2003): "Modest Policy Interventions," Journal of Monetary Economics, 50(8), 1673-1700.

Liu, Z., D. Waggoner, and T. Zha (2008): "Has the Federal Reserve's Inflation Target Changed?," Manuscript, Emory University and the Federal Reserve Bank of Atlanta.

Liu, Z., D. F. Waggoner, And T. Zha (2007): "Asymmetric Expectation Effects of Regime Shifts and the Great Moderation," Working Paper 653, Federal Reserve Bank of Minneapolis.

Lubik, T. A., And F. Schorfheide (2004): "Testing for Indeterminacy: An Application to U.S. Monetary Policy," American Economic Review, 94(1), 190-219.

LuCAs, R. E. (1976): "Econometric Policy Evaluation: A Critique," in CarnegieRochester Conference Series on Public Policy, Vol. 1: The Phillips Curve and Labor Markets, ed. by K. Brunner, and A. Meltzer. North-Holland, Amsterdam, Holland.

McCallum, B. T. (1983): "On Non-Uniqueness in Rational Expectations Models: An Attempt at Perspective," Journal of Monetary Economics, 11(2), 139-168.

Mishkin, F. S. (2004): "Why the Federal Reserve Should Adopt Inflation Targeting," International Finance, 7(1), 117-127.

RotemberG, J. J., And M. Woodford (1997): "An Optimization-Based Econometric Framework for the Evaluation of Monetary Policy," in NBER Macroeconomics Annual, ed. by B. S. Bernanke, and J. J. Rotemberg, pp. 297-346. MIT Press, Cambridge, MA. 
SARgent, T. J. (1984): "Auroregressions, Expectations, and Advice," American Economic Review, 74(2), 408-415.

Schorfheide, F. (2005): "Learning and Monetary Policy Shifts," Review of Economic Dynamics, 8(2), 392-419.

Sims, C. A. (1982): "Policy Analysis with Econometric Models," Brookings Papers on Economic Activity, 1, 107-164.

(1987): "A Rational Expectations Framework for Short-Run Policy Analysis," in New Approaches to Monetary Economics, ed. by W. A. Barnett, and K. J. Singleton, pp. 293-308. Cambridge University Press, Cambridge, England.

Sims, C. A., And T. Zha (2006): "Were There Regime Switches in U.S. Monetary Policy?," American Economic Review, 96(1), 54-81.

Smets, F., And R. Wouters (2007): "Shocks and Frictions in US Business Cycles: A Bayesian DSGE Approach," American Economic Review, 97, 586-606.

Stock, J. H., and M. W. Watson (2003): "Has the Business Cycles Changed? Evidence and Explanations," in Monetary Policy and Uncertainty: Adapting to a Changing Economy, pp. 9-56. Federal Reserve Bank of Kansas City, Jackson Hole, Wyoming.

Svensson, L. E., And N. Williams (2005): "Monetary Policy with Model Uncertainty: Distribution Forecast Targeting," Manuscript, Princeton University.

Woodford, M. (2003): Interest and Prices: Foundations of a Theory of Monetary Policy. Princeton University Press, Princeton, NJ.

Federal Reserve Bank of San Francisco and Emory University, Federal Reserve Bank of Atlanta, Federal Reserve Bank of Atlanta and Emory University 